\title{
Alterações micrometeorológicas em vinhedos pelo uso de coberturas de plástico
}

\author{
Loana Silveira Cardoso(1), Homero Bergamaschi(1), Flávia Comiran(1), Geraldo Chavarria(1), \\ Gilmar Arduíno Bettio Marodin(1), Genei Antônio Dalmago(2) ${ }^{(2)}{ }^{(1)}$ rique Pessoa dos Santos ${ }^{(3)}$ e Francisco Mandelli(3) \\ (1) Universidade Federal do Rio Grande do Sul, Faculdade de Agronomia, Avenida Bento Gonçalves, no 7712, CEP 91540-000 Porto Alegre, \\ RS. E-mail: loanacar@yahoo.com.br, homerobe@ufrgs.br, flaviacomiran@gmail.com, geraldochavarria@hotmail.com, marodin@ufrgs.br \\ (2)Embrapa Trigo, BR 285, Km 294, CEP 99001-970 Passo Fundo, RS. E-mail: dalmago@cnpt.embrapa.br (3)Embrapa Uva e Vinho, Caixa \\ Postal 130, CEP 95700-000 Bento Gonçalves, RS. E-mail: henrique@cnpuv.embrapa.br, mandelli@cnpuv.embrapa.br
}

Resumo - O objetivo deste trabalho foi avaliar os efeitos da cobertura de plástico sobre alguns elementos meteorológicos que formam o microclima de vinhedos de Vitis vinifera L., cultivar Moscato Giallo, em Flores da Cunha, na Serra Gaúcha. O experimento foi conduzido na safra 2005/2006, com os tratamentos: fileiras de plantas descobertas; e fileiras de plantas cobertas com plástico transparente tipo ráfia, com $160 \mu \mathrm{m}$ de espessura. Medições contínuas de radiação fotossinteticamente ativa, temperatura e umidade do ar, e velocidade do vento foram realizadas: acima da cobertura; entre a cobertura e o dossel; sobre o dossel descoberto; e junto aos cachos de ambos tratamentos. Estimou-se a evapotranspiração de referência nos dois tratamentos. Da radiação fotossinteticamente ativa incidente, $67,5 \%$ chegou ao dossel coberto, $16 \%$ atingiu os cachos cobertos e $36 \%$ chegou aos cachos descobertos. A cobertura aumentou em $3,4^{\circ} \mathrm{C}$ as temperaturas máximas do ar junto às plantas. A umidade relativa do ar diurna foi menor, enquanto a pressão de vapor e o deficit de saturação foram superiores debaixo da cobertura. A velocidade do vento foi reduzida pela cobertura em $88 \%$. No ambiente coberto, a evapotranspiração de referência foi $65 \%$ daquela do ambiente externo. Embora aumente as temperaturas diurnas, a cobertura de plástico promoveu redução na demanda evaporativa do vinhedo.

Termos para indexação: Vitis vinifera, microclima, micrometeorologia, plasticultura.

\section{Micrometeorological alterations in vineyards by using plastic covering}

\begin{abstract}
The objective of this work was to evaluate the effects of plastic covering on the microclimate of vineyards (Vitis vinifera L., cultivar Moscato Giallo), in Serra Gaúcha region in Rio Grande do Sul State, Brazil. The experiment was performed in Flores da Cunha, RS, during the 2005/2006 growing season. It comprised uncovered and covered rows of vines, using a $160 \mu \mathrm{m}$ thick plastic film. Photossinthetically active radiation (PAR), air temperature and humidity, and wind velocity were monitored: over the plastic covering; between the film and the canopy; over the uncovered canopy; and close to grapes of both treatments. Reference evapotranspiration was estimated for both treatments. From the incoming PAR, $67.5 \%$ reached the covered canopy, $16 \%$ reached the covered grapes, and 36\% reached the uncovered grapes. The plastic covering increased by $3.4^{\circ} \mathrm{C}$ the maximum air temperatures close to plants. Diurnal air relative humidity was reduced, while water vapor pressure and vapor pressure deficit were increased because of the plastic covering, which also reduced in $88 \%$ the wind velocity in comparison to open air. The reference evapotranspiration on the covered canopy was $35 \%$ lower than in open air. Although increasing diurnal air temperatures, the plastic covering may reduce the evaporative demand on vineyards, by reducing the incoming solar radiation and the wind velocity.
\end{abstract}

Index terms: Vitis vinifera, microclimate, micrometeorology, plasticulture.

\section{Introdução}

O Rio Grande do Sul é o principal produtor nacional de uvas para a agroindústria, e a Serra Gaúcha é a principal zona produtora; com clima temperado, esta região responde por $84 \%$ da área vitícola do Estado e
90\% da produção de vinhos finos do País (Miele et al., 2003).

As condições climáticas da área de cultivo são determinantes da qualidade da uva. A Serra Gaúcha apresenta níveis adequados de temperatura e radiação solar para o cultivo de videiras. No entanto, excessos 
de umidade, em particular durante a maturação, favorecem a ocorrência de doenças fúngicas que afetam a qualidade das uvas e do vinho (Miele et al., 2003). Por este motivo, o cultivo em ambientes protegidos pode contribuir para a melhoria da qualidade da produção. Embora existam poucas informações técnicas, muitos produtores da região já utilizam cobertura de plástico em vinhedos, para reduzir excessos de precipitação sobre as plantas, eliminar risco de perdas por granizo, e obter melhor qualidade das uvas.

A adoção de cultivos protegidos tem sido uma forma de melhorar a qualidade de diversos produtos agrícolas, mediante alterações micrometeorológicas. Condições de radiação solar, temperatura e umidade relativa do ar podem ser modificadas pelo uso de coberturas de plástico. Os filmes de polietileno de baixa densidade, utilizados amplamente em estufas, apresentam transmissividade mínima de 65\% e máxima de $90 \%$ para radiação solar (Farias et al., 1993a; Camacho et al., 1995; Beckmann et al., 2006). Reisser Júnior (2002) observou transmissividade média $70 \%$ de radiação fotossinteticamente ativa, em estufas de polietileno de baixa densidade (PEBD). Farias et al. (1993a) observaram aumento na radiação difusa, que passou de $24 \%$ da radiação global ao ar livre para $45 \%$ em ambiente protegido, para dias ensolarados.

Alterações na temperatura do ar, em ambientes protegidos, estão relacionadas ao balanço de energia, que é influenciado pelo tipo de cobertura, ângulo de incidência da radiação solar, tamanho e abertura das cortinas laterais. Farias et al. (1993b) observaram aumentos de 1,2 a $4,4^{\circ} \mathrm{C}$ na temperatura máxima do ar, no interior de estufa de plástico, em comparação ao ambiente externo. Porém, as temperaturas mínimas são menos influenciadas, e não apresentam diferença entre ambientes internos e externos (Buriol et al., 1993).

A umidade relativa do ar no interior de estufas, em geral, é superior à do ambiente externo, em consequiência do aumento da concentração ou pressão de vapor d'água (Farias et al., 1993b; Schiedeck et al., 1997). No entanto, para períodos diurnos, Buriol et al. (2000) observaram menor umidade relativa no interior de estufas, acompanhado de acréscimos na temperatura do ar, sobretudo em dias de céu limpo, dependentes do manejo das aberturas.

Em virtude das alterações micrometeorológicas, têmse observado reduções em torno de $70 \%$ na evapotranspiracão das culturas em estufas de plástico, em comparação a cultivos a céu aberto (Farias et al., 1994; Dalmago et al., 2006).
Os estudos feitos em cultivos sob estufas de plástico demonstram que é possível alterar favoravelmente o microclima de vinhedos, por meio de coberturas impermeáveis e translúcidas, instaladas somente sobre as fileiras de plantas e abertas nas laterais. Entretanto, considerando-se as especificidades deste novo sistema, faz-se necessário caracterizar detalhes e quantificar os padrões relativos às alterações micrometeorológicas; como no caso de estufas de plástico, cuja utilização em vinhedos pode alterar a disponibilidade de radiação solar, a temperatura, a umidade do ar, e a velocidade do vento junto ao dossel. O presente estudo teve como objetivo avaliar os efeitos da cobertura de plástico sobre alguns elementos meteorológicos que formam o microclima de vinhedos de Vitis vinifera L., cultivar Moscato Giallo, em Flores da Cunha, na Serra Gaúcha.

\section{Material e Métodos}

O estudo foi realizado em área da Vinícola Giacomin $\left(29^{\circ} 6\right.$ 'S, $51^{\circ} 20^{\prime} \mathrm{W}$, altitude $\left.541 \mathrm{~m}\right)$, em Flores da Cunha, RS, na safra 2005/2006. O clima da região é temperado, do tipo $\mathrm{Cfb}$ (Köppen), com precipitação de $1.736 \mathrm{~mm}$, distribuída durante o ano, e temperatura média anual de $15^{\circ} \mathrm{C}$. A cultivar utilizada foi Moscato Giallo (clone VCR 1), sobre porta-enxerto Kobber 5BB. Esta é uma cultivar de Vitis vinifera, com baga de película branca e destinada à elaboração de vinhos e espumantes moscatéis. O vinhedo apresentava densidade de 3.700 plantas por ha, com espaçamento de $0,9 \mathrm{~m}$ na linha e $3 \mathrm{~m}$ nas entrelinhas. $\mathrm{O}$ sistema de condução utilizado foi em forma de $Y$, pelo qual a vegetação é conduzida em duas cortinas inclinadas. O sistema consiste de um suporte de concreto no formato de $\mathrm{Y}$, com haste de $1,10 \mathrm{~m}$ de altura, e braços laterais de $0,80 \mathrm{~m}$ distanciados na suas extremidades em 1,30 m. Aparafusados aos braços de cada Y, estendem-se para fora hastes de madeira de 0,50 $\mathrm{m}$ de comprimento, aos quais é fixada uma estrutura de madeira em forma de $\mathrm{V}$ invertido, para formar uma cumeeira de 2,4 $\mathrm{m}$ de altura, sobre a qual é instalada a cobertura de plástico. A largura da cobertura é de 2,40 m entre as duas extremidades laterais.

$\mathrm{O}$ experimento foi implantado em um vinhedo de sete anos, e seu delineamento consistiu de duas áreas contíguas, que representaram os tratamentos com e sem cobertura de plástico. A área sem cobertura continha cinco fileiras de plantas, enquanto a área coberta tinha 12 fileiras. Cada fileira continha 40 plantas, espaçadas em $0,9 \mathrm{~m}$. Para a cobertura, utilizou-se um filme de 
plástico transparente tipo ráfia, de $160 \mu \mathrm{m}$ de espessura, com aditivos anti-UV e antigotejo. Toda a área experimental havia sido coberta na safra anterior (2004/2005) com o mesmo tipo de plástico, que foi retirado das cinco fileiras iniciais, antes da poda.

Em 1@/9/2005, realizou-se a poda mista nas plantas, tendo-se deixado uma média de quatro varas (cinco gemas) e sete a dez esporões (duas gemas) por planta. Durante o ciclo vegetativo-produtivo, efetuou-se a poda verde em $4 / 11 / 2005$, tendo-se mantido os ramos dentro do sistema de condução.

Logo após a poda, foram instalados sensores, ao longo do perfil do dossel, para o monitoramento micrometeorológico. Foram medidos: a radiação fotossinteticamente ativa (RFA), 400-700 nm, com barras providas de células fotovoltaicas; temperatura e umidade do ar, com psicrômetros de pares termoelétricos; e a velocidade do vento, com anemômetros de conchas. A RFA, temperatura e umidade do ar foram medidas: acima da cobertura de plástico; entre a cobertura e o dossel; acima do dossel descoberto; e na altura dos cachos de ambos tratamentos. A velocidade do vento foi medida entre a cobertura e o dossel e acima do dossel descoberto, à mesma altura acima do solo. Os sensores foram conectados a "dataloggers" Campbell CR21X, com leituras a cada $30 \mathrm{~s}$ e as médias foram armazenadas a cada $30 \mathrm{~min}$. Foram calculadas médias diárias, decendiais e mensais, e o desvio-padrão das variáveis monitoradas. A evapotranspiração de referência foi calculada segundo Penman (1948), para ambos tratamentos. Junto ao experimento, instalou-se uma estação meteorológica automática, para monitoramento meteorológico do local.

\section{Resultados e Discussão}

O período experimental teve médias mensais de radiação solar global, temperaturas média e mínima, umidade do ar e velocidade do vento semelhantes às normais da região (Embrapa, 2006). Destacou-se o mês de outubro, com precipitação pluvial de $371 \mathrm{~mm}$, superior à média climática da região, que é de $185 \mathrm{~mm}$. De novembro a fevereiro a precipitação mensal ficou em torno de $90 \mathrm{~mm}$, abaixo da média regional que fica próxima a $140 \mathrm{~mm}$ por mês. As médias mensais das temperaturas máximas do ar foram de $30^{\circ} \mathrm{C}$, enquanto as normais foram em torno de $27^{\circ} \mathrm{C}$.
A radiação fotossinteticamente ativa (RFA) variou de 4,9 $\mathrm{MJ} \mathrm{m}^{-2}$ por dia, em outubro, a 9,7 $\mathrm{MJ} \mathrm{m}^{-2}$ por dia, em novembro e dezembro, com distribuição semelhante à radiação global. Na média do período experimental, a RFA correspondeu a $43 \%$ da radiação solar global (Figura 1). Também no Rio Grande do Sul, França et al. (1997) obtiveram uma razão de $42 \%$ entre RFA e radiação global, durante o ciclo do milho. Em Pelotas, RS, Assis \& Mendez (1989) observaram que a RFA foi cerca de $47 \%$ da radiação global.

A cobertura de plástico reduziu a radiação incidente sobre o dossel coberto. Entre a cobertura e o dossel, a RFA foi $67,5 \%$ da incidente sobre a cobertura, tendo variado de 62 a 75\% (Figura 2). Farias et al. (1993a) observaram transmissividade média de $83 \%$ em polietileno de baixa densidade. Em vinhedo sob cobertura de plástico em Jundiaí, SP, Lulu \& Pedro Júnior (2006) observaram transmissividade de $73 \%$ da radiação solar global. Reisser Júnior (2002) observou transmissividade média diária de $70 \%$ da RFA em estufas de plástico.

A menor disponibilidade de RFA em ambiente protegido, em relação ao ambiente externo, é atribuída à reflexão e à absorção pela cobertura. Os valores obtidos no presente trabalho são inferiores aos observados por Farias et al. (1993a) e Buriol et al. (1995), o que pode ser atribuído às diferenças no plástico da cobertura, sobretudo quanto à espessura e à presença de faixas mais opacas formadas pela malha de ráfia, que não aparecem no PEBD extrusado e liso, comumente utilizado em estufas.

A disponibilidade de RFA, na altura dos cachos descobertos, diminuiu de $98 \%$, no início do ciclo, para $17 \%$ após o terceiro decêndio de outubro, para média

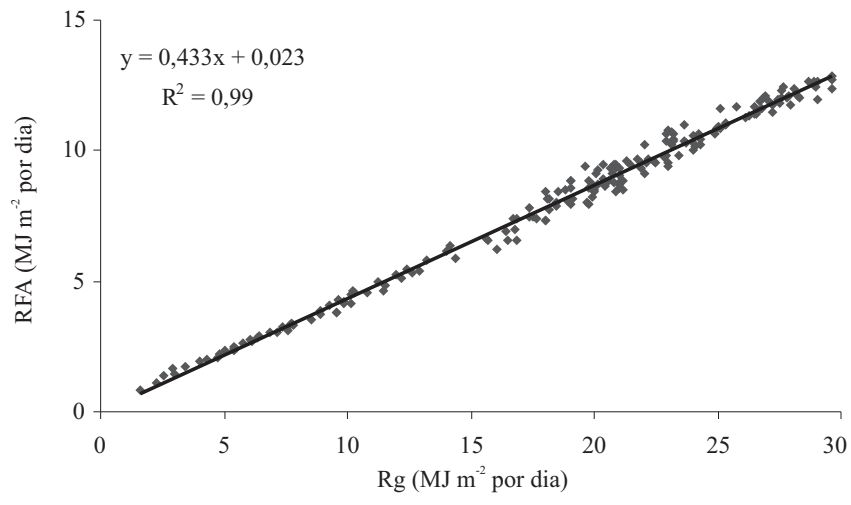

Figura 1. Relação entre totais diários de radiação fotossinteticamente ativa (RFA) incidente e radiação solar global (Rg), de setembro a março. 
de $36 \%$ em todo período avaliado (Figura 2). Esta redução na disponibilidade de radiação, no nível dos cachos, demonstra que houve aumento no sombreamento causado pelo dossel, pelo crescimento vegetativo. Teixeira \& Lima Filho (1997) observaram redução na transmissão de RFA de 87 para $34 \%$ no nível dos cachos, durante o ciclo da cultivar Itália, conduzida em latada sem cobertura de plástico, em Petrolina, PE. Neste trabalho, a evolução de RFA, na altura dos cachos cobertos, foi semelhante, porém com maior redução, em razão do efeito conjunto da cobertura de plástico e do próprio dossel (Figura 2). Na média do período, a RFA incidente no nível dos cachos cobertos foi $16 \%$ daquela que incidiu sobre a cobertura de plástico, tendo variado de 58\%, no início do ciclo, a aproximadamente $6 \%$ no restante do período. Este padrão de atenuação da radiação está de acordo com os resultados de Lulu \& Pedro Júnior (2006), que observaram redução gradativa da radiação global, por efeito apenas da cobertura de plástico, e da atenuação conjunta da cobertura de plástico e do dossel vegetal.

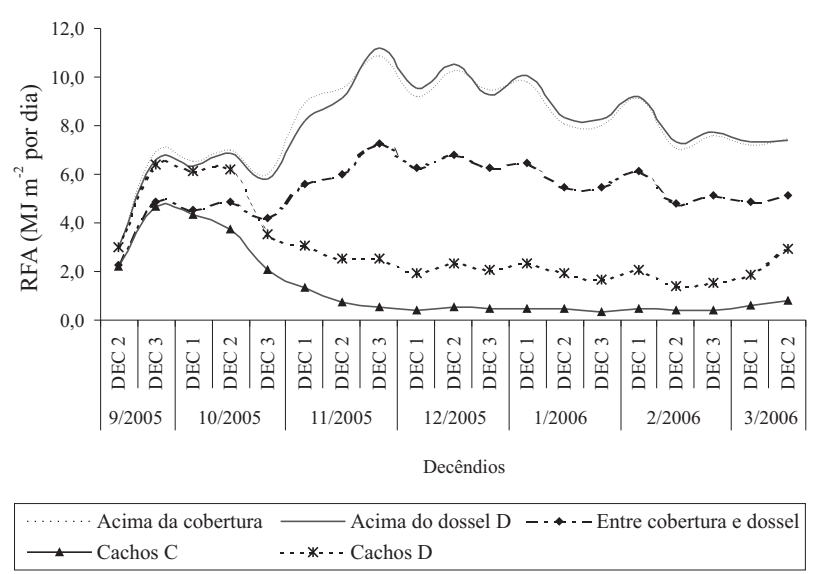

Figura 2. Médias decendiais de radiação fotossinteticamente ativa (RFA) incidente, em diferentes alturas, em vinhedo com (C) e sem (D) cobertura de plástico.
Temperaturas do ar mais elevadas ocorreram no tratamento coberto, entre a cobertura e o dossel, seguido daquelas na altura dos cachos cobertos. A cobertura provocou acréscimo médio de $3,4^{\circ} \mathrm{C}$ nas temperaturas máximas junto às plantas, que passou de $28,4^{\circ} \mathrm{C}$, acima da cobertura, para $31,8^{\circ} \mathrm{C}$ entre a cobertura e o dossel, na média do período (Tabela 1). Resultados semelhantes foram obtidos por Farias et al. (1993b), que evidenciaram aumentos significativos da temperatura máxima do ar pela cobertura de plástico.

Os maiores efeitos da cobertura sobre a temperatura do ar ocorreram em períodos diurnos, o que proporcionou maiores alterações nas temperaturas máximas do que nas mínimas. Em todo o período, as diferenças nas temperaturas mínimas atingiram somente $0,6^{\circ} \mathrm{C}$, entre o nível dos cachos cobertos e o ambiente externo. Este padrão de alteração na temperatura do ar, entre ambientes coberto e descoberto, é coerente com as observações de Buriol et al. (1993), que atribuíram pequeno efeito de estufas de plástico sobre as temperaturas mínimas.

O maior aquecimento diurno do ar, sob as coberturas de plástico, pode ser relacionado ao menor volume de ar a ser aquecido, em relação ao ambiente externo, em razão da menor movimentação do ar junto à superfície por efeito da própria cobertura de plástico (Buriol et al., 1997). Em todo o período, a velocidade média do vento foi de $0,91 \mathrm{~m} \mathrm{~s}^{-1}$, junto ao dossel descoberto, e $0,09 \mathrm{~m} \mathrm{~s}^{-1}$ abaixo da cobertura de plástico, com redução de $88 \%$ (Figura 3). A máxima velocidade foi de $8,9 \mathrm{~m} \mathrm{~s}^{-1}$ na área descoberta, no dia 29/9/2005. No mesmo dia, a velocidade máxima debaixo da cobertura foi de $3 \mathrm{~m} \mathrm{~s}^{-1}$. Resultados semelhantes foram obtidos por Cunha \& Escobedo (2003), em estufa de plástico com cultivo de pimentão, em Botucatu, SP.

Com variações inversas à temperatura do ar, a umidade relativa foi maior em períodos noturnos, tendo atingido aproximadamente $93 \%$ das 21 às $8 \mathrm{~h}$, mas tendo decrescido durante o dia para aproximadamente $74 \%$

Tabela 1. Médias diárias e desvios-padrão (DP) da temperatura do ar máxima, mínima e média $\left({ }^{\circ} \mathrm{C}\right)$, de setembro de 2005 a março de 2006, em diferentes alturas de vinhedos com e sem cobertura de plástico.

\begin{tabular}{|c|c|c|c|c|c|c|c|c|c|c|}
\hline \multirow[t]{2}{*}{ Variável } & \multicolumn{2}{|c|}{ Acima da cobertura } & \multicolumn{2}{|c|}{$\begin{array}{c}\text { Entre cobertura e } \\
\text { dossel }\end{array}$} & \multicolumn{2}{|c|}{ Cachos cobertos } & \multicolumn{2}{|c|}{$\begin{array}{c}\text { Acima do dossel } \\
\text { descoberto }\end{array}$} & \multicolumn{2}{|c|}{ Cachos descobertos } \\
\hline & Média & DP & Média & DP & Média & DP & Média & DP & Média & DP \\
\hline Temperatura máxima & 28,4 & 4,3 & 31,8 & 5,0 & 29,7 & 4,3 & 28,0 & 4,4 & 28,6 & 4,4 \\
\hline Temperatura mínima & 14,8 & 2,7 & 14,7 & 2,6 & 15,2 & 2,7 & 14,5 & 2,6 & 14,5 & 2,6 \\
\hline Temperatura média & 20,3 & 3,0 & 21,2 & 3,2 & 20,8 & 3,1 & 20,2 & 3,2 & 20,2 & 3,1 \\
\hline
\end{tabular}


(Figura 4). A variação diária da umidade relativa média do ar foi diferente entre tratamentos e posições avaliadas no dossel. Em períodos diurnos, menores valores ocorreram entre a cobertura e o dossel, com valor mínimo de $63 \%$, enquanto na altura dos cachos descobertos, os valores ficaram em torno de $70 \%$, próximo às $15 \mathrm{~h}$.

Os valores de pressão real de vapor no ar foram semelhantes em todas alturas avaliadas, em períodos noturnos (Figura 4). Durante o dia, a maior pressão de vapor ocorreu entre a cobertura e o dossel e na altura dos cachos cobertos, tendo sido 0,3 MPa maior que a pressão medida acima do dossel descoberto e acima da cobertura. A pressão de vapor variou de $1,75 \mathrm{MPa}$, durante a noite, a 2,30 MPa à tarde, quando ocorreram as maiores temperaturas.

O deficit de saturação de vapor d'água no ar apresentou diferenças mais distintas entre tratamentos do que a umidade relativa. Entre a cobertura e o dossel, variação média do deficit de saturação foi de 2,4 MPa em períodos diurnos (Figura 4). Nas horas mais quentes do dia, o deficit de saturação foi até 3,7 MPa superior, entre a cobertura e o dossel, em relação ao nível dos cachos descobertos. À noite, o deficit de saturação teve pequena diferença entre tratamentos, cujos valores, entre a cobertura e o dossel, foram 0,3 MPa inferiores ao ambiente externo.

Ao se analisar em conjunto a pressão real de vapor, o deficit de saturação de vapor d'água e a umidade relativa do ar, verificou-se que, embora a umidade relativa do ar tenha sido inferior debaixo da cobertura, em períodos diurnos, houve maior pressão de vapor d'água e maior deficit de saturação do vapor d'água nesse ambiente. Esta inversão se justifica, pois, para um mesmo conteúdo

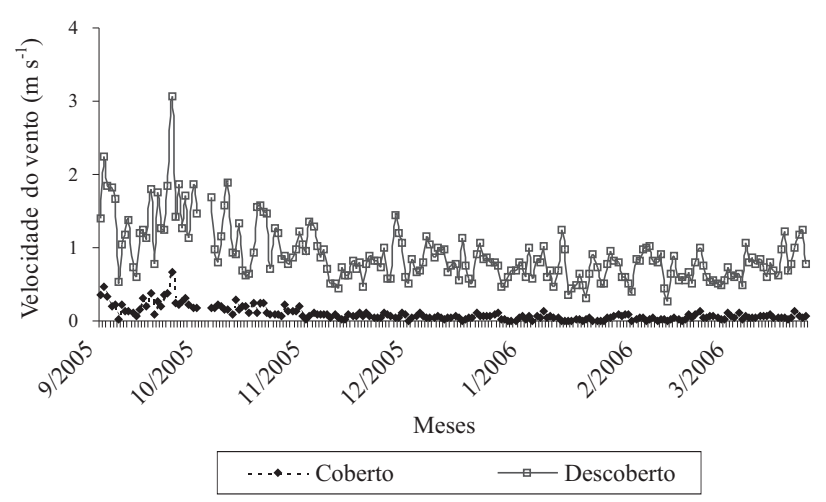

Figura 3. Médias diárias de velocidade média do vento a $2 \mathrm{~m}$ de altura, em vinhedos com e sem cobertura de plástico. de vapor d'água no ar, a umidade relativa é inversamente proporcional à temperatura do ar, e esta foi mais elevada debaixo da cobertura, em períodos diurnos.

A evapotranspiração de referência (ETo) é indicadora da demanda evaporativa atmosférica. Observou-se que a ETo foi maior no tratamento descoberto do que debaixo da cobertura, em todo o período avaliado. Os valores máximos de ETo na área descoberta foram de $6,4 \mathrm{~mm}$ por dia, com média de 3,7 $\mathrm{mm}$ por dia. Debaixo da cobertura, o valor máximo de ETo foi de $4,2 \mathrm{~mm}$ por dia e sua média ficou em $2,4 \mathrm{~mm}$ por dia. O parâmetro angular da função que relaciona valores de evapotranspiração de referência, nas áreas coberta e descoberta (Figura 5), demonstra que, debaixo da cobertura, ela foi $65 \%$ da observada no ambiente externo.
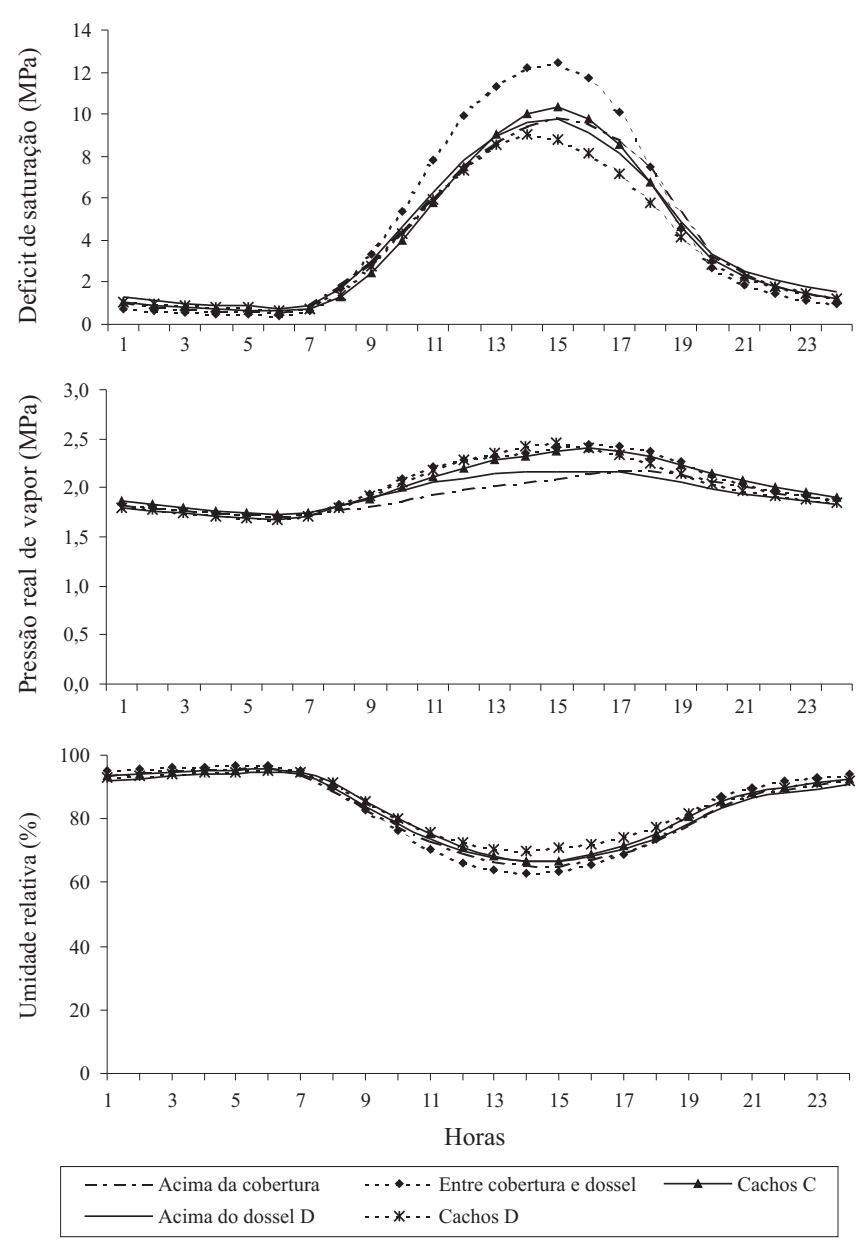

Figura 4. Médias horárias de umidade relativa do ar, pressão real de vapor e deficit de saturação de setembro de 2005 a março de 2006, em diferentes alturas de vinhedos com (C) e sem (D) cobertura de plástico. 


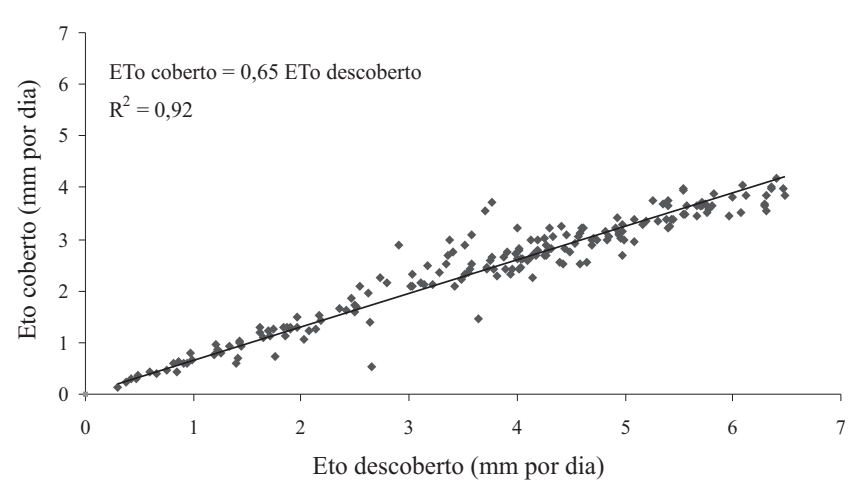

Figura 5. Razão entre totais diários de evapotranspiração de referência (ETo), em vinhedos com e sem cobertura de plástico.

Segundo Farias et al. (1994), a cobertura de plástico reduz a demanda evaporativa atmosférica, especialmente em razão da atenuação da radiação e da diminuição da velocidade do vento, considerados como fatores mais importantes na demanda evaporativa atmosférica. Valores semelhantes foram encontrados por Martins \& Gonzalez (1995) em estufa de plástico, onde a evapotranspiração de referência no ambiente interno foi aproximadamente $60 \%$ da observada a céu aberto.

\section{Conclusões}

1. A cobertura de plástico, do tipo ráfia, reduz em cerca de $33 \%$ a disponibilidade de radiação fotossinteticamente ativa incidente sobre o dossel.

2. Coberturas de plástico sobre filas de videiras impõem barreira física ao vento e reduzem sua velocidade em cerca de $90 \%$.

3. O uso de cobertura de plástico sobre vinhedos causa aumento da temperatura do ar, com maior efeito sobre as temperaturas diurnas do que sobre as noturnas.

4. Em períodos diurnos, a umidade relativa do ar é inferior debaixo da cobertura de plástico, em relação ao ambiente externo; contudo, a cobertura de plástico provoca aumentos na pressão real de vapor e no deficit de saturação do ar, durante o dia.

5. A cobertura de plástico reduz em cerca de um terço a demanda evaporativa atmosférica, em relação ao ambiente externo.

\section{Referências}

ASSIS, F.N. de; MENDEZ, M.E.G. Relação entre radiação fotossinteticamente ativa e radiação global. Pesquisa Agropecuária Brasileira, v.24, p.797-800, 1989.

BECKMANN, M.Z.; DUARTE, G.R.B.; PAULA, V.A. de; MENDEZ, M.E.G.; PEIL, R.M.N. Radiação solar em ambiente protegido cultivado com tomateiro nas estações verão-outono do Rio Grande do Sul. Ciência Rural, v.36, p.86-92, 2006.

BURIOL, G.A.; LUFT, S.V.L.; HELDWEIN, A.B.; STRECK, N.A.; SCHNEIDER, F.M. Efeito da ventilação sobre a temperatura e umidade do ar em túneis baixos de polietileno transparente e o crescimento da alface. Revista Brasileira de Agrometeorologia, v.5, p.17-24, 1997.

BURIOL, G.A.; RIGHI, E.Z.; SCHNEIDER, F.M.; STRECK, N.A.; HELDWEIN, A.B.; ESTEFANEL, V. Modificação da umidade relativa do ar pelo uso e manejo da estufa plástica. Revista Brasileira de Agrometeorologia, v.8, p.11-18, 2000.

BURIOL, G.A.; SCHNEIDER, F.M.; ESTEFANEL, V.; ANDRIOLO, J.L.; MEDEIROS, S.L.P. Modificação na temperatura mínima do ar causada por estufas de polietileno transparente de baixa densidade. Revista Brasileira de Agrometeorologia, v.1, p.43-49, 1993.

BURIOL, G.A.; STRECK, N.A.; PETRY, C.; SCHNEIDER, F.M. Transmissividade à radiação solar do polietileno de baixa densidade utilizado em estufas. Ciência Rural, v.25, p.1-4, 1995.

CAMACHO, M.J.; ASSIS, F.N. de; MARTINS, S.R.; MENDEZ, M.E.G. Avaliação de elementos meteorológicos em estufa plástica em Pelotas, RS. Revista Brasileira de Agrometeorologia, v.3, p.19-24, 1995.

CUNHA, A.R. da; ESCOBEDO, J.F. Alterações micrometeorológicas causadas pela estufa plástica e seus efeitos no crescimento e produção da cultura de pimentão. Revista Brasileira de Agrometeorologia, v.11, p.15-27, 2003.

DALMAGO, G.A.; HELDWEIN, A.B.; NIED, A.H.; GRIMM, E.L.; PIVETTA, C.R. Evapotranspiração máxima da cultura de pimentão em estufa plástica em função da radiação solar, da temperatura, da umidade relativa e do deficit de saturação do ar. Ciência Rural, v.36, p.785-792, 2006.

EMBRAPA. Normal climatológica: estação agroclimática da Embrapa Uva e Vinho, Bento Gonçalves, RS: dados médios do período de 1961 a 1990. Passo Fundo: Embrapa Uva e Vinho, 2006. Disponível em: http://www.cnpuv.embrapa.br/ meteorologia/bento-normais.html. Acesso em: 12 dez. 2006.

FARIAS, J.R.B.; BERGAMASCHI, H.; MARTINS, S.R. Evapotranspiração no interior de estufas plásticas. Revista Brasileira de Agrometeorologia, v.2, p.17-22, 1994.

FARIAS, J.R.B.; BERGAMASCHI, H.; MARTINS, S.R.; BERLATO, M.A. Efeito da cobertura plástica de estufa sobre a radiação solar. Revista Brasileira de Agrometeorologia, v.1, p.31-36, 1993a.

FARIAS, J.R.B.; BERGAMASCHI, H.; MARTINS, S.R.; BERLATO, M.A.; OLIVEIRA, A.C.B. Alterações na 
temperatura e umidade relativa do ar provocadas pelo uso de estufa plástica. Revista Brasileira de Agrometeorologia, v.1, p.51-62. 1993b.

FRANÇA, S.; ROSA, L.M.G.; BERGAMASCHI, H.; NABINGER, C.; SPANENNBERG, P. Radiação fotossinteticamente ativa e sua relação com a radiação solar global em dossel de alfafa, em função do índice de área foliar. Revista Brasileira de Agrometeorologia, v.5, p.147-153, 1997.

LULU, J.; PEDRO JÚNIOR, M.J. Microclima de vinhedos cultivados sob cobertura plástica e a céu aberto. Revista Brasileira de Agrometeorologia, v.14, p.106-115, 2006.

MARTINS, S.R.; GONZALEZ, J.F. Evapotranspiração e respostas fisiológicas do feijão-vagem em substrato em estufa com sistema de ventilação/calefação. Revista Brasileira de Agrometeorologia, v.3, p.31-37, 1995.

MIELE, A.; GUERRA, C.C.; HICKEL, E.; MANDELLI, F.; MELO, G.W.; KUHN, G.B.; TONIETTO, J.; PROTAS, J.F. da S.; MELLO, L.M.R. de; GARRIDO, L. da R.; BOTTON, M.; ZANUS, M.C.;
SÔNEGO, O.R.; SORIA, S. de J.; FAJARDO, T.V.M.; CAMARGO, U.A. Uvas viníferas para processamento em regiões de clima temperado. Bento Gonçalves: Embrapa Uva e Vinho, 2003. (Embrapa Uva e Vinho. Sistema de Produção, 4).

PENMAN, H.L. Natural evaporation from open water, bare soil and grass. Proceedings of the Royal Society of London: Series A, v.193, p.120-145, 1948.

REISSER JÚNIOR, C. Alterações físicas em ambientes de estufa plástica e seus efeitos sobre as condições hídricas e o crescimento do tomateiro. 2002. 160p. Tese (Doutorado) Universidade Federal do Rio Grande do Sul, Porto Alegre.

SCHIEDECK, G.; MIELE, A.; BARRADAS, C.I.N.; MANDELLI, F. Fenologia da videira 'Niágara Rosada' cultivada em estufa e a céu aberto. Revista Brasileira de Agrometeorologia, v.5, p.199-206, 1997.

TEIXEIRA, A.H.C. de; LIMA FILHO, J.M.P. Relações entre o índice de área foliar e radiação solar na cultura da videira. Revista Brasileira de Agrometeorologia, v.5, p.143-146, 1997.

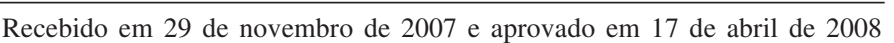

